\title{
EFFECT OF TEACHING MODULES ABOUT BRONCHIAL ASTHMA CARE ON SAFETY NURSING PRACTICE Reham El-Ashery Ashery Asker ${ }^{1^{*}}$, Amany Mohamed Shebl ${ }^{2}$, Wafaa Ismail Shrief ${ }^{3,}$ Karima Fouad Elshamy ${ }^{4}$, Amira Ahmed Hassanein ${ }^{5}$ \\ 1 Assistant lecturek,Faculty of Nursing, Fayuam University. $2,3,4,5$ of Medical Surgical Nursing, Faculty of Nursing, Mansoura University E-mail of the corresponding author: Reham.elashery@yahoo.com
}

\begin{abstract}
Asthma has a profound impact on all aspects of a patient's life. Nursing safety practice has an important role on maintaining health, preventing complications. The aim of this present study was to safety nursing practice establish, implement and evaluate the effect of implementing teaching modules for patient with bronchial asthma on at Mansoura University Hospitals. A quasi-experimental research design was used in this study on a subject: 50 nurses; 25 nurses at Mansoura University Hospital (Chest Unit \& Chest ICU), and 25 nurses at Emergency Hospital (Outpatient Department and ICU) were recruited. Two tools were used to collect data; bronchial asthma safety nursing performance observation checklist and bronchial asthma safety nursing practice knowledge assessment in addition to the teaching modules of bronchial asthma nursing care developed by the researcher based on the result of the nurses' performance. The result In preImplementation phase, only $18 \%$ of nurses had adequate total correct knowledge and less than one third $(32 \%)$ of the nurses achieved done correctly level of practice regarding safety practice care of patients with bronchial asthma. While, post-Implementation, the majority of the nurses had adequate total correct knowledge and done correctly level of practice regarding care of patients with bronchial asthma (94\%\& 96\%) respectively. There was extremely highly statistically significant relation between nurses, level of practice and their knowledge. Study concluded that, implementing teaching modules about bronchial asthma care was effective and there was significant relation between nurses, performance before and after implementing teaching modules about safety practice for bronchial asthma. The present study recommended, in-service educational programs and update of guidelines for nurses regarding care safety practice of patients with bronchial asthma should be available.
\end{abstract}

Keywords: Bronchial asthma \& Safety practice nursing.

\section{Introduction:}

Asthma is a serious health problem throughout the world, so public attention in the developed world has recently focused on asthma because of its rapidly increasing prevalence (1). Around 300 million patients worldwide suffer from bronchial asthma and an additional 100 million may be diagnosed with asthma by 2025 . In 2009, 250000 patients died of asthma, which is expected to become the third leading cause of death in the world by $2030(2,3)$.

In USA, according to Centers for Disease Control and Prevention (4), asthma affects nearly 22 million Americans, $10 \%$ of all age currently had asthma. The Global Initiative for Asthma ${ }^{(5)}$ stated that in Arabic region, the prevalence of asthma differs from country to another. In Lebanon, it was $7.2 \%$, Kuwait 8.5\%, United Arab Emirates 6.2\%, 
Saudi Arabia 5.6\%, Tunisia 4.3\%, Algeria $3.9 \%$, and in Morocco, it was 3.8\%.

In Egypt, the World health organization (3) estimated that chronic respiratory diseases account for $6.9 \%$ $(27.7 \times 103)$ of diseases and also osteoarthritis, injuries and asthma (15.3 $\mathrm{x} 103$ ) are the leading causes of disability. In Mansoura, the Chest Hospital and Emergency Department in 2011 reported that approximately two thirds of total patients (24880) patients and only 2316 patients were admitted in inpatients units, diagnosed bronchial asthma ${ }^{(8)}$.

Despite its increasing prevalence, however, there has been a recent decline in mortality ${ }^{(6)}$. In 2012 there were 10.6 million physician office visits, 1.2 million hospital outpatient department visits and almost 1.7 million emergency room visits due to asthma. Also, the annual financial impact of asthma is $\$ 20$ billion in direct care and lost productivity ${ }^{(4,7)}$.

Asthma has been increasing, it occurs across the life span, from the very young to the very old. It is a highly complex disorder that involves biochemical, familial, immunologic, endocrine, infectious, autonomic, psychological factors, allergenic and environmental factors that can be mild or a very serious and life threatening condition, but it probably varies from patient to patient and in the same patient from episode to episode ${ }^{(9)}$. The symptoms of asthma can usually be controlled with a combination of drugs and environmental changes ${ }^{(3)}$.

Asthma is a chronic inflammatory disorder of the airways in which many cells and cellular elements play a role. The chronic inflammation is associated with airway hyper responsiveness, mucosal edema, and mucus production that lead to recurrent episodes of wheezing, breathlessness, chest tightness, cough and dyspnea, particularly at night or in early morning by a variety of triggering stimuli resulting in partially or completely reversible bronchoconstriction ${ }^{(\mathbf{1 0}, \mathbf{5})}$.

The diagnosis depend on history, physical examination and pulmonary function tests. Treatment involves controlling triggering factors and drug therapy, most commonly with inhaled $\beta_{2^{-}}$ agonists and inhaled corticosteroids. Prognosis is good with treatment. Asthma is more acute and intermittent than chronic obstructive pulmonary disease (COPD), even though it can be chronic ${ }^{(11)}$.

Asthma differs from other obstructive lung diseases in that it is a reversible process either spontaneously or with treatment so, effective and rapid treatment is vital. It involves the immunologic system and the autonomic nervous system ${ }^{(\mathbf{1 2})}$. It is an autoimmune disease that the body is reacting in a hypersensitive way to specific substances or triggers that most others would consider harmless. When asthma is triggered, an asthma attack is usually looming. An asthma attack can happen within minutes of exposure to an allergen and can be fatal if not treated immediately ${ }^{(\mathbf{1 3})}$.

Teaching is crucial to how nurses practice, talk and write about keeping patients safe. Ultimately, teaching should empower nurses to positively affect the prevention, promotion, maintenance or modification of illness. Also, it is an integral part of the nursing process and nurse can use this process to assess, plan, implement and evaluate an effective and individualized teaching program ${ }^{(\mathbf{1 2})}$.

Nursing care is based on early management of patients during acute attack is individualized depending on age, type of asthma and severity of illness. Nurse can manage patients with asthma through assessment of respiratory system, giving adequate hydration, promoting airway clearance, improving of breathing, and finally providing support to patient and family ${ }^{(12)}$. Meanwhile, the nurse should observe patient's condition after 
Effect of Teaching Modules about Bronchial Asthma etc...

providing care in order to evaluate such improvement. Nurses don't acts only as care providers but also as educators for patients and their families ${ }^{(9)}$.

\section{Significance of the study}

In Egypt, by ${ }^{(14)}$ study done by Ashery (2011), it was reported that, more than eighty percentage of the nurses $(82 \%)$ had inadequate level of knowledge and more than two thirds of the nurses $(68 \%)$ had inadequate level of total practice in caring for patients with bronchial asthma.

Teaching modules about bronchial asthma care and bronchial asthma nursing care guidelines are very important to enhance and maintain competency of care based on scientific evidence of knowledge and practice ${ }^{(\mathbf{9}) .}$

The nurses play a vital role in preventing asthma attacks or decreasing its severity focusing on teaching modules about bronchial asthma care for prevention and control of asthma in order to reduce the disability and mortality related to asthma, so nurses need safe and efficient interventions ${ }^{(3)}$. So, teaching modules about bronchial asthma care should receive ongoing attention in order to ensure standardized, effective and up-todate safety nursing practice.

Nurses can undertake much of the health promotion work of general practice and have a leading role in the management of chronic diseases such as asthma, diabetes, and coronary heart disease. Depending on the complexity of tasks, degree of autonomy, and level of training, care may be provided by nurse practitioners ${ }^{(15)}$. Disseminating national guidelines is not enough. Providing educational training and guideline-specific resources, in combination with tools for practice change, improved care significantly even in safety net health centers serving high-disparity patient populations (16). Education and standardization efforts to increase uniformity of practice are worth considering in other practice areas to increase safety and possibly reduce costs (17).

Therefore the present study was conducted to investigate the effect of implementing teaching modules about bronchial asthma care on safety nursing practice at Mansoura University Hospitals.

\section{Subjects and Methods \\ Research design}

Quasi-experimental research design was utilized in this study during a period of 12 months from August 2012 till July 2013.

\section{Research Setting:}

This study was conducted on nurses working and provides direct care in: (Chest Unit, and Outpatient Department of Mansoura University Hospitals.

The chest diseases department provides medical services to patients with chest diseases. Patients are admitted to the department through the outpatient chest clinic of Mansoura University Hospital or through the outpatient department of Emergency Hospital.

\section{Subjects:}

All available nurses (50 nurses) who provide direct care for bronchial asthma patients in the previously mentioned settings and accepted to participate voluntary and gave consent were recruited in the study.

\section{Hypothesis:}

There will be an improvement of nurses, performance pre, post implementation of teaching modules about bronchial asthma care on safety nursing practice

\section{Variables:}

Nurses exposed to teaching modules about bronchial asthma care show high level of knowledge mean score.

Tools and techniques of data collection: 
Two tools were used for data collection in addition to the developed teaching modules about bronchial asthma care:

I. Bronchial asthma safety nursing practice knowledge assessment: It was developed by the researcher after reviewing relevant recent literature. It included two main parts: knowledge to disease and safety nursing practice, it consists of 52 main questions, in addition socio-demographic characteristics of nurses under study.

II. Bronchial asthma safety nursing performance observation checklist about the care of bronchial asthma patients: it consists of 186 items and divided into 9 main parts: safety oxygen therapy (35 items), safety positioning (5items), safety diaphragmatic breathing and cough (19 items), safety steps for using the inhaler ( 8 items), nebulizer (27 items), safety naso-tracheal suction (31 items), safety end-tracheal suction (26 items), safety peak flowmeter (9 items), safety incentive spirometry (26 items).

\section{Method}

Three main phases were used for data collection:-

\section{Preparatory phase}

- An official permission to conduct the study was obtained from the directors of the hospitals in the above mentioned setting after explanting the aims and nature of the study.

- Tools were developed by the researcher based on recent and relevant literatures, reference ${ }^{(\mathbf{7 , 9 1 2})}$.

- Tools validity and reliability were be ascertained. Tool were tested for their content validity by five experts in the field of this study for clarity, relevance, comprehensiveness, and ease for administration. Minor modifications were required.
- Verbal consent of participants was obtained after explanting the aims of the study.

- The pilot study was conducted on 5 nurses $(10 \%)$ of the total sample to evaluate the clarity, feasibility, and applicability of the tools, necessary modifications were done accordingly. Those nurses were excluded from the main study sample.

- A colored booklet was developed to the distributed to participate

\section{Operational phase:} Pre implementation phase (Initial assessment )

A- Assessment of nurses' performance

- Assessment of nurses' performance was done by the researcher through indirect observation, it was done three days/week during morning and afternoon shifts for about 5 hours/ day.

- $\quad$ The researcher observed 2-3 nurses' practice each visit.

- Each nurse was observed in the most of the procedures.

- Each nurse was observed 3 times for every procedure during different shifts and the average score was taken.

- Nurses were not aware that they were observed.

B- Assessment of nurses' knowledge

- Nurses' knowledge were assessed nurses.

- Answering questions requires about 30- 45 minutes.

- Nurses knowledge was assessed through distributed the study tool I in the presence of the nurses reschedule and asked them to return it back.

C- Teaching modules about bronchial asthma care

Teaching modules about safety practice bronchial asthma care were developed by the researcher based on the 
Effect of Teaching Modules about Bronchial Asthma etc...

result of the nurses' performance, their needs of knowledge and practice.

Implementation phase (Intervention):

- Nurses were divided into in small groups (5-10 nurses/session) according to their time schedule.

- Six sessions were conducted over 2 consecutive weeks.

- Each session lasted for 30 to 45 minutes.

- Explanation of the teaching modules were conducted using power point presentation, audiovisual materials, video tape, discussion, demonstration and redemonstration were also conducted during each session.

- Implementation of teaching modules about bronchial asthma care content (tool III) which included sixth sessions that divided in two types of sessions: educational and training sessions.

- Teaching modules about bronchial asthma care booklet was given to each nurse to grasp her attention, motivate her, and to be as a reference.

- Each nurse in study group was seen continuously by the researcher to be sure that the instructions were followed correctly. Correction, reinstruction and re-demonstration were offered.

\section{Evaluation phase:}

- Evaluation of nurses' knowledge using tool I through self- administered questionnaire after implementing

- Teaching modules about bronchial asthma care sessions.

- Evaluation of nurses' performance was observed by the researcher using tools II.

- Comparison of each nurse's findings with the preceding one to evaluate the effect of implementing teaching modules about bronchial asthma care on safety nursing practice

\section{Ethical considerations}

A verbal consent was obtained from each participant after explanting the aims \& nature of the study. They were assured that anonymity \& confidentiality and privacy would be guaranteed and that they have the right to withdraw from the study at any time without giving any reason.

\section{Statistical analysis}

Data entry and analysis were done using the Statistical Package for Social Sciences (SPSS), version 15. Data were presented using descriptive statistics in the form of frequencies and percentages for qualitative variables, and means and standard deviations for quantitative variables. Qualitative categorical variables were compared using chi-square test.

Statistical significance was considered at p-value $\leq 0.05$ at confidence interval $95 \%$ and non-significant difference was considered at $\mathrm{P}>0.05$. Collected data were statistically analyzed, presented in tables \& graphs and used appropriate reliable, valid statistical methods \& tests. Graphs were done for data visualization and using Microsoft Excel.

Results:

\section{Socio-demographic characteristics}

Figure (1-4)

Most of the nurses (64\%) were in the age group $20<30$ years. Moreover, less than half of the nurses had bachelor degree, while, less than two fifths of them had secondary school and less than fifth of the nurses are technical nursing institute graduates $\quad(46 \%, \quad 38 \% \quad \& \quad 16 \%)$ respectively. More than half of the nurses are nursing supervisors $(52 \%)$ and the remaining of them $(48 \%)$ are staff nurses. Nearly one third of the nurses $(32 \%)$ had more than 6 years of experience. The most of the nurses $(76 \%)$ didn't attend any nursing training courses

Table (1) depicts that, in preimplementation phase, only $18 \%$ of nurses 
had adequate total correct knowledge regarding care of patients with bronchial asthma, while in the immediate and postimplementation phases, their knowledge were improved to $92 \%$ and $94 \%$ respectively. There was a statistically significant difference between preimplementation, immediate, and postimplementation phases in the total nurses' knowledge $(\mathrm{P}=0.00)$.

Table (2) illustrates that, in preimplementation phase only $(32 \%)$ of the nurses, while the majority of nurses $(96 \%)$ in immediate and post- implementation phase achieved done correctly level of practice. There was a statistically significant relation between preimplementation, immediate and postimplementation total nurses' practice.

Table (3) indicates that, nurses, practice level pre-implementation phase in relation to, naso-tracheal suctioning, diaphragmatic breathing and coughing exercise, positioning, using nebulizer, endotracheal suctioning, oxygen therapy, using the inhaler, using incentive spirometry, and a peak flowmeter were satisfactory level of practice as observed in 50\%, $48 \%, 44 \%$, $26 \%, \quad 20 \%, \quad 16 \%, \quad 14 \%, \quad 0 \% \quad \& \quad 0 \%$ respectively. While, in the immediate and post implementation phase, majority of the nurses were improved practice level and done correctly.

Table (4) shows that, there were a statistically significant difference in nurses their total knowledge about bronchial asthma pre, immediate, and postimplementation phases in relation to educational level, occupation, attendance of training course and department of work $(\mathrm{P}<0.05)$. While there were no statistically significant differences with other sociodemographic characteristics of nurses and their knowledge $(\mathrm{P}>0.05)$.

Table (5) shows that, there were statistically significant difference in total nurses' practice in relation to demographic characteristics in pre, immediate and post guidelines implementation phases in to; educational level, occupation and attendance of training course.

This table (6) shows that there was extremely highly statistically significant relation between nurses, level of practice and their knowledge between preimplementation, immediate and postimplementation phases of bronchial asthma guidelines

Frequency Distribution of Nurses According to Their Related Age

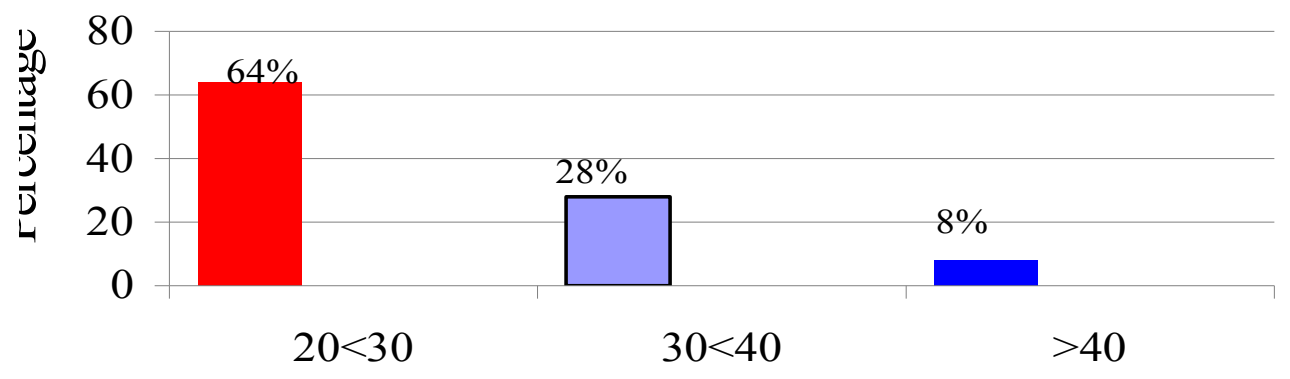

Age (in Years)

Mean \pm SD $=29.48 \pm 10.1$

Figure (1): Frequency Distribution of Nurses According to Their Related Age (in Years) among Nurses $(\mathrm{n}=50)$ 


\section{Frequency Distribution of Nurses}

According to Educational Level

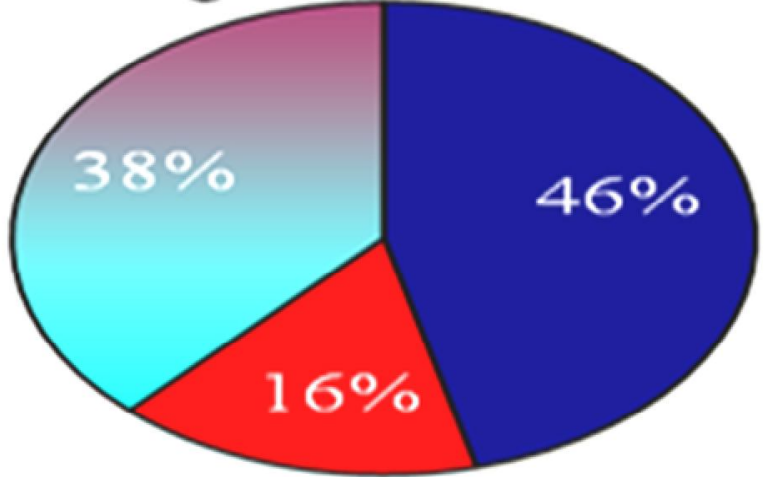
- Bachelor
$\square$ Technical Institute
$\square$ Secondary School

Figure (2): Frequency Distribution of According to Their Education Level of Nurses ( $\mathrm{n}=50)$

Frequancy Distribution of Nurses According to Their Post

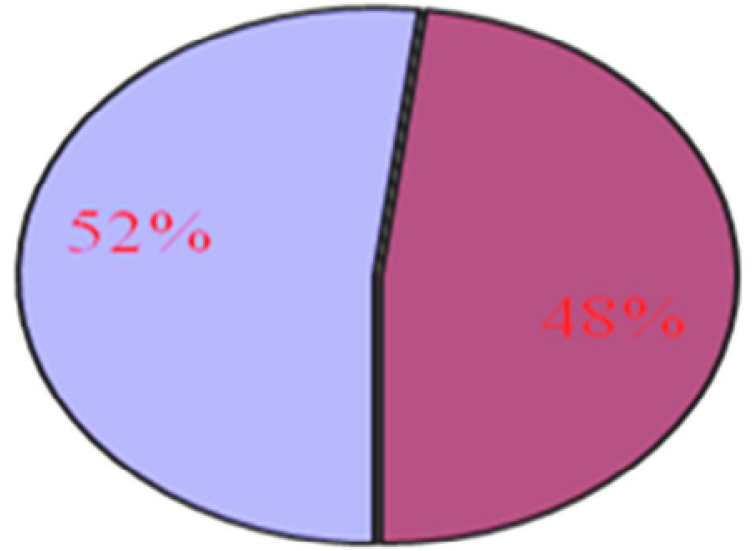

\section{$\square$ Nursing Supervisors $\square$ Staff Nurse}

Figure (3): Frequency Distribution of According to Their Post of Nurses $(\mathrm{n}=50)$ 


\section{Frequency Distribution of Nurses According to Their} Experience

$32 \%$

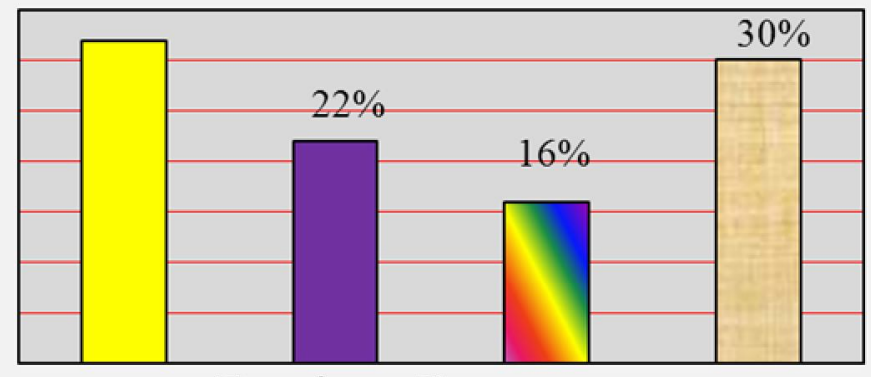

Experience Years

$\square<2$ years $\quad \square 2<4$ years $\square 4<6$ years $\square$ More than 6 years

Figure (4): Frequency Distribution of Nurses According to Their Experience $(n=50)$

Table (1): Frequency Distribution of Total Adequate Level of Knowledge of Nurses about Care of Patients with Bronchial Asthma Pre, Immediate, and Post Guidelines Implementation $(\mathrm{n}=50)$

\begin{tabular}{|c|c|c|c|c|c|c|c|}
\hline \multirow{2}{*}{$\begin{array}{l}\text { Level of Nurses' } \\
\text { Knowledge }\end{array}$} & \multicolumn{2}{|c|}{$\begin{array}{c}\text { Pre- } \\
\text { Implementation }\end{array}$} & \multicolumn{2}{|c|}{$\begin{array}{c}\text { Immediate } \\
\text { Implementation }\end{array}$} & \multicolumn{2}{|c|}{$\begin{array}{c}\text { Post- } \\
\text { Implementation }\end{array}$} & \multirow[t]{2}{*}{$\begin{array}{c}\text { P- } \\
\text { value }\end{array}$} \\
\hline & No. & $\%$ & No. & $\%$ & No. & $\%$ & \\
\hline Adequate & 9 & 18 & 46 & 92 & 47 & 94 & $\begin{array}{c}0.00 * \\
*\end{array}$ \\
\hline Mean \pm SD $=$ & \multicolumn{2}{|c|}{$.360 \pm .776$} & \multicolumn{2}{|c|}{$1.840 \pm .548$} & \multicolumn{2}{|c|}{$1.860 \pm .588$} & \\
\hline
\end{tabular}

Table (2): Frequency Distribution of Nurses According to Total Safety Nurses' Practice Mean Score Regarding Pre, Immediate and Post Teaching of Patients with Bronchial Asthma $(n=50)$

\begin{tabular}{|c|c|c|c|c|c|c|c|}
\hline $\begin{array}{c}\text { Level of Nurses' } \\
\text { Practice }\end{array}$ & \multicolumn{2}{|c|}{$\begin{array}{c}\text { Pre- } \\
\text { Implementation }\end{array}$} & \multicolumn{2}{c|}{$\begin{array}{c}\text { Immediate } \\
\text { Implementation }\end{array}$} & \multicolumn{2}{c|}{$\begin{array}{c}\text { Post- } \\
\text { Implementation }\end{array}$} & \multirow{2}{*}{$\begin{array}{c}\text { P- } \\
\text { value }\end{array}$} \\
\cline { 2 - 7 } & No. & \% & No. & \% & No. & \% & \\
\hline Done correctly & 16 & 32 & 48 & 96 & 48 & 96 & \multirow{2}{*}{..00** $^{* *}$} \\
\hline Mean \pm SD $=$ & \multicolumn{2}{|c|}{$.180 \pm .388$} & \multicolumn{2}{|c|}{$.960 \pm .197$} & $.960 \pm .197$ & \\
\hline
\end{tabular}


Effect of Teaching Modules about Bronchial Asthma etc...

Table (3): Frequency Distribution of Nurses According to Their Safety Nursing Practice Level for pre immediate and post teaching of Patient with Bronchial Asthma $(n=50)$

\begin{tabular}{|c|c|c|c|c|c|c|c|}
\hline \multirow{3}{*}{$\begin{array}{l}\text { Variable of practice } \\
\text { (1) Positioning }\end{array}$} & \multirow{2}{*}{\multicolumn{2}{|c|}{$\begin{array}{c}\text { Pre- } \\
\text { Implementation } \\
\text { Satisfactory level } \\
\text { No. } \%\end{array}$}} & \multirow{2}{*}{\multicolumn{2}{|c|}{$\begin{array}{c}\text { Immediate } \\
\text { Implementation } \\
\text { Satisfactory level } \\
\text { No. } \%\end{array}$}} & \multirow{2}{*}{\multicolumn{2}{|c|}{$\begin{array}{c}\text { Post- } \\
\text { Implementation } \\
\text { Satisfactory } \\
\text { level } \\
\text { No. } \%\end{array}$}} & \multirow{3}{*}{$\begin{array}{c}\begin{array}{c}\text { P- } \\
\text { value }\end{array} \\
.01\end{array}$} \\
\hline & & & & & & & \\
\hline & 22 & 44 & 48 & 96 & 47 & 94 & \\
\hline (2) Oxygen therapy & 8 & 16 & 47 & 94 & 48 & 96 & .43 \\
\hline $\begin{array}{l}\text { (3) Using } \\
\text { nebulizer }\end{array}$ & 13 & 26 & 48 & 96 & 48 & 96 & .13 \\
\hline $\begin{array}{l}\text { (4) Diaphragmatic } \\
\text { breathing \& } \\
\text { coughing exercise }\end{array}$ & 24 & 48 & 49 & 98 & 48 & 96 & .56 \\
\hline $\begin{array}{l}\text { (5) Naso-tracheal } \\
\text { suctioning }\end{array}$ & 25 & 50 & 48 & 96 & 48 & 96 & .21 \\
\hline $\begin{array}{l}\text { (6) Endotracheal } \\
\text { suctioning }\end{array}$ & 10 & 20 & 47 & 94 & 48 & 96 & .01 \\
\hline $\begin{array}{l}\text { (7) Using the } \\
\text { inhaler }\end{array}$ & 7 & 14 & 49 & 98 & 49 & 98 & .012 \\
\hline $\begin{array}{l}\text { (8) Using a peak } \\
\text { flowmeter }\end{array}$ & 0 & 0 & 48 & 96 & 47 & 94 & $0.00 * *$ \\
\hline $\begin{array}{l}\text { (9) Using Incentive } \\
\text { spirometry }\end{array}$ & 0 & 0 & 47 & 94 & 48 & 96 & $0.00 * *$ \\
\hline
\end{tabular}


Reham El-Ashery Ashery Asker et. al.

Table (4): Relation between Total Nurses' Knowledge about safety nursing practice and Their Socio-Demographic Characteristics about Bronchial Asthma Pre, Immediate, and Post Guidelines Implementation $(\mathrm{n}=50)$

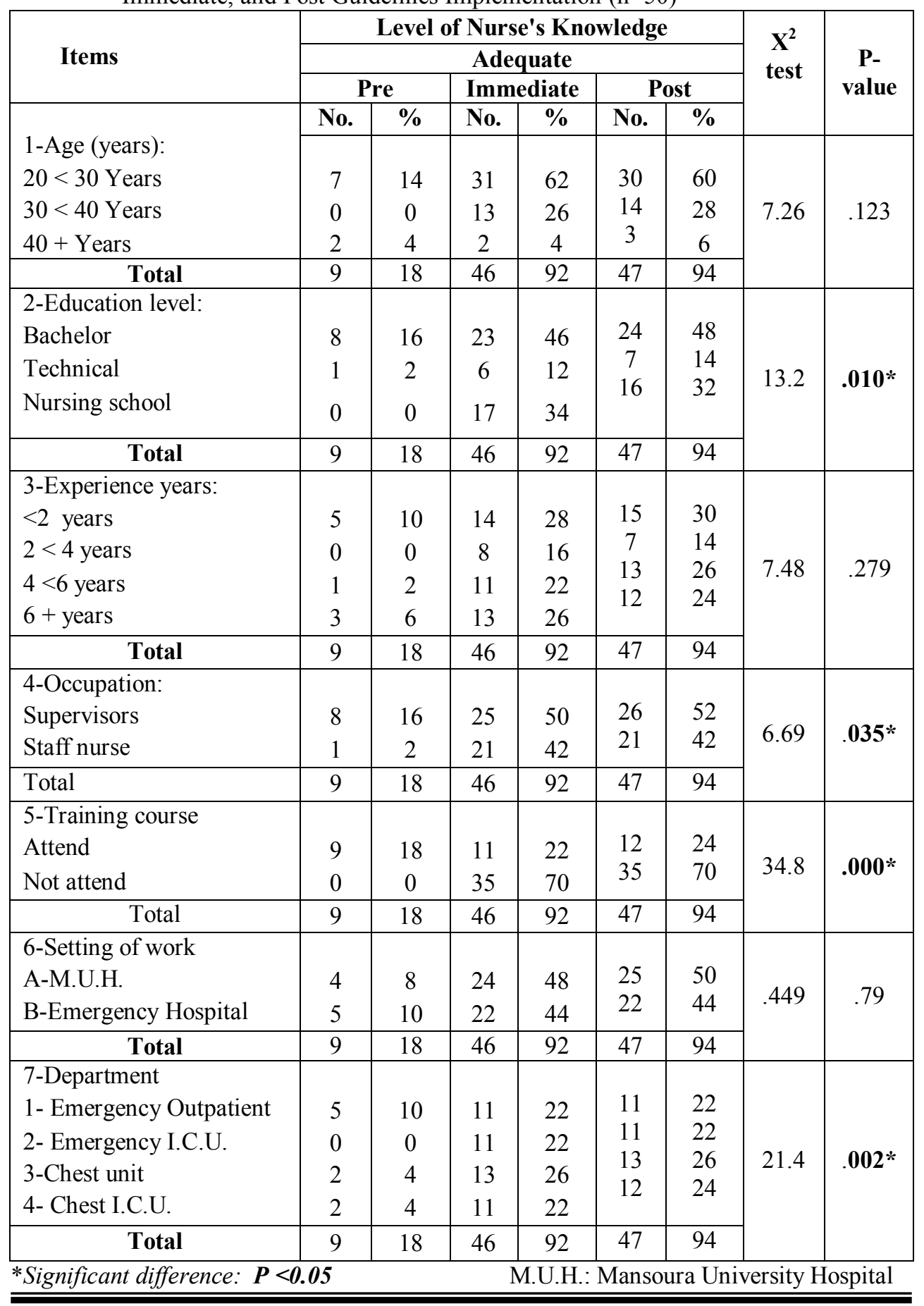


Effect of Teaching Modules about Bronchial Asthma etc...

Table (5): Relation between Total Nurses' Safety Practice and Their Socio- Demographic Characteristics $(\mathrm{n}=50)$

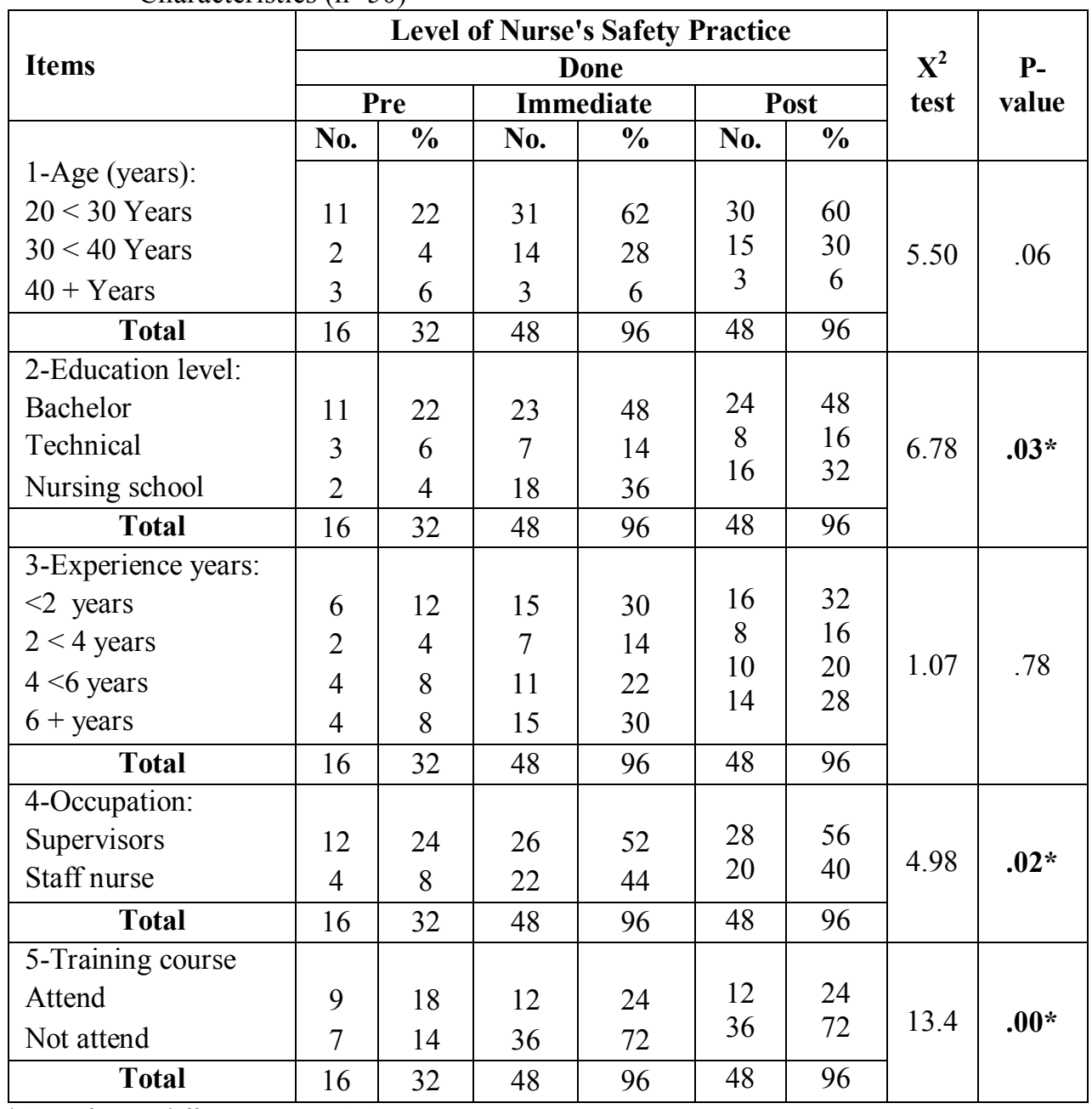

*Significant difference: $\boldsymbol{P}<\mathbf{0 . 0 5}$

Table (6): Relation between Nurses, Knowledge and Safe Nursing Practice Regarding Care of Patients with Bronchial Asthma Pre, Immediate and Post $(n=50)$

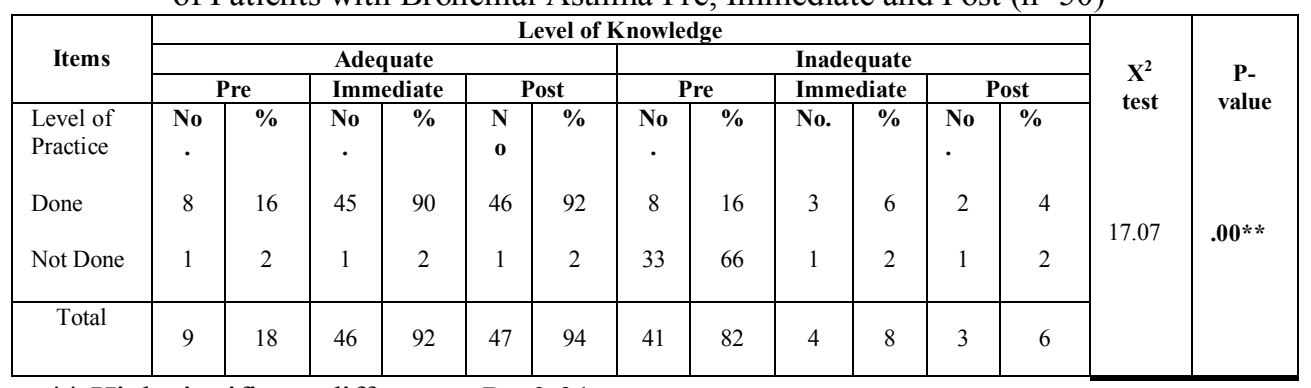

** High significant difference: $\mathrm{P}<0.01$ 


\section{Discussion:}

In relation to nurses, characteristics, the present study revealed that less than half of nurses had a bachelor degree. Incongruent with the previous findings, ${ }^{(18)}$ found in her study about care of patients with respiratory distress that the majority of nurses had a nursing diploma. As regards years of experience of nurses, the present study finding revealed that nearly one third of the nurses had more than 6 years of experience. Similarly, ${ }^{(19)}$ showed that half of nurses have bachelor degree and the other half have diploma of nursing. But regarding experience in ICU, less than half of them have less than 2 years of experience and about seventy percent of them aged more than 25 years.

The result of the current study revealed that, only minority of nurses had adequate total correct knowledge regarding safety practice with bronchial asthma. The researcher attributed this finding to the lack of training safety programs related to respiratory diseases which might rehabilitate the nurse to provide optimal care.

Research finding illustrated that less than half of nurses had average level of knowledge regarding safety nursing practice. As well, ${ }^{(20,21)}$ more than two thirds of nurses had poor knowledge regarding care given to patients.

The current study showed that, majority of the nurses, practice level in relation to safety nursing practice about using peak flowmeter, incentive spirometry, inhaler, oxygen therapy and endotracheal suctioning was inadequate safety nursing practice and for less than half of them in relation to position, diaphragmatic breath and cough exercise and naso-tracheal suctioning their safety practice level was inadequate. Similarly, (20) result found that nurses, performance safety toward oxygen mask, nasal cannula, naso-tracheal suctioning, and endotracheal suctioning for patients with bronchial asthma was poor but nurses, performance in nebulizer was average. In agreement with this present study finding (21), found that majority of nurses was revealed inadequate practice level as regards oxygen therapy and chest physiotherapy.

In relation to total nurses, practice mean score regarding care patients with bronchial asthma, the present study revealed that only less than one third of the nurses had achieved according to level of practice. This may be attributed to lack of training safety to of nursing staff, and lack of supervision or no available manual book for nursing performance. This result was in agreement with, ${ }^{(15)}$, who found that almost all of nurses had poor practice score regarding care of patients with pneumonia at Sharkia Governorate hospitals. Similarly, ${ }^{(\mathbf{1 8 . 1 9 . 2 1 )}}$, revealed that all nurses had inadequate performance and knowledge pre-program implementation.

All nurses didn't use peak flow meter and spirometry despite of the presence of two apparatus in Allergy and Chest unit. This may be attributed lack of knowledge to the importance of peak flow meter and spirometry. Moreover, ${ }^{(22)}$, identified that spirometry should be measured at initial assessment, post therapy when the peak flow is stabilized, and then every 1-2 years. As well, ${ }^{(23)}$ stated that efficacy of spirometry in diagnosing severe asthma has already been demonstrated. However, (12), larified that daily peak flow monitoring is recommended for all patients with moderate or severe asthma because it helps to assess asthma severity and indicates the current degree of asthma control. Additionally, ${ }^{(24)}$, stated that a peak flow meter is most helpful for patients and doctors to learn what makes asthma worse, decide treatment plan and when to seek care. 
Effect of Teaching Modules about Bronchial Asthma etc...

The finding illustrated that nurses did not follow antiseptic techniques as washing hands and changing gloves, suction catheter, oxygen mask, nebulizer cup and $\mathrm{O} 2$ humidifier daily or between patients and also used tap water due to insufficient time, shortage of equipment, carelessness, lack of knowledge regarding importance of hand washing, lack of attitude and healthy habits, work overload and absence of good role model or close supervision for nurses, performance. These results agree with ${ }^{\mathbf{( 2 5 . 2 6 )}}$, they observed that the majority of nurses didn't follow the principles of aseptic technique by using unsterile mask and also from patient to another. On contrary, ${ }^{(27)}$, showed that the universal precautions action related to wearing gloves safety was adequate for more than two third of the studied nurses.

Moreover, (28.29) reported that the proper hand washing technique is the single greater measures that can be employed to prevent the spread of diseases. As well, (20), showed that most of studied nurses used sterile gloves when contacting with blood and when performing sterile procedures for selfprotection against infection. On the same line, (21),found that all nurses had inadequate safety practice in relation to hand washing. On contrary, ${ }^{(30)}$, stated that the water of oxygen therapy should be changed daily and humidifier should be cleaned with detergent.

Training program would be a method which should continuously be provided to update and improve the nurses' knowledge and practice. The present study revealed that there was statistically significant relation between nurses, attendance of training program and total knowledge and total practice. Similarly, ${ }^{\mathbf{( 2 6 . 3 1 )}}$, found that there was a statistically significant difference between nurses, attendance of training program to their knowledge and skills. On contrary, ${ }^{(21)}$,found that there was no statistically significant relation between nurses, knowledge and practice regarding their previous training courses. Additionally, in a recent study, (32), mentioned that continuing nursing education programs must include planned learning activities to provide knowledge, skills for enhancement of nursing practice.

Finally, statistical analysis of this study revealed that there was a positive statistically significant relation between nurses, level knowledge and their practice which means that when knowledge of nurses increases the performance respectively improved. This finding emphasized that both knowledge and practice are equally important in the work of the nurse, and the focus should be on knowledge utilization clinical nursing requires that the nurse to incorporate knowledge and skills into practice. This again clarified the importance of in-service training, and continuing nursing education. Similarly, (19.20.22) showed that a highly positive relation was found between knowledge and practical among nurses. This result was in accordance with ${ }^{\mathbf{( 2 1 . 3 3 )}}$, they found that there was a highly statistically significant relation between nurses, knowledge and their practice.

\section{Conclusion:}

In the light of the present study findings, it can be concluded that:

In pre-Implementation phase, only minority of nurses had adequate total of nurses knowledge mean score and less than one third $(32 \%)$ of the nurses had correctly level of practice regarding care of patients with bronchial asthma. While, post-Implementation, the majority of the nurses had adequate total correct knowledge and done correctly level of practice regarding care of patients with bronchial asthma (94\%\& 96\%) respectively

There was extremely highly statistically significant relation between nurses' level of practice and their 
knowledge pre immediate, and post implementing teaching modules about safety practice for care of patients with bronchial asthma.

\section{Recommendations:}

On the basis of the most important findings of the current study, the following recommendations are suggested:

- Continuous in-service educational programs and updated guidelines, for nurses regarding safety nursing practice of patients with bronchial.

- Training program about safety nursing practice should be carried out for newly recruited nurses in any chest unit or outpatient clinical.

1. Inservice training programm for nurses about safety practice for care of patients with bronchial asthma should carried out.

2. Guidline about safety practice for care of patients with bronchial asthma in each chest unit shold be available.

\section{References:}

1. Lilly, C., (2011): Diversity of asthma: Evolving concepts of pathophysiology and lessons from genetics. J. Allergy Clin. Immunol; 115: S526-31.

2. Fanta, C. (2011): Asthma. New England Journal of Medicine 360 (10): Available at 1002-14. doi:10.1056/NEJMra0804579.

PMID 19264689." Accessed on May 5, 2013.

3. World Health Organization (WHO) (2013): World health statistics. Geneva, Available at: http://www.who.int/whosis/whostat/2 008/en/index.html. Accessed on May 5, 2013.

4. Centers for Disease Control and Prevention (CDC) (2012):Asthma Incidence And Prevalence, National Center for Health Statistics. National Ambulatory Medical Care survey, 2006-2012. National Hospital
Ambulatory Medical Care Survey,

available at:

http://www.cdc.int/whosis/whostat/20

08/en/index.html

5. GINA, (2013): The global burden of asthma report. Available at: http://www.ginasthma.org. Accessed on May 9, 2013.

6. National Heart, Lung, and Blood Institute (2012): Global strategy for diagnosis, management, and prevention of chronic obstructive pulmonary disease. NIH Pub No. 2701. Available at: http://www.goldcopd.com/ guidelineitem.asp?11=2\&12=1\&intid $=989$ Accessed on 3-9-2013.

7. Sullivan, A. (2012): A profile of US Asthma Centers, 2009. Ann Allergy Asthma Immunol; 99:419.

8. Statistical Records of Mansoura Chest Hospital, (2013).

9. Linton, A. (2011): Introduction to medical surgical nursing, (4th ed.). U.S.A.: Elsevier Inc., 550-60.

10. McCance, K., and Huether, S. (2011): Understanding pathophysiology, (4th ed.). China: Mosby Inc., Elsevier Inc., $126-30$.

11. Asthma and Allergy Foundation of America (2013): Asthma: What causes asthma. Available at http://www.aafa.org. Retrieved on 219-2013.

12. Bare, B., Smeltzer, S. (2010): Brunner and Suddarth's textbook of medical surgical nursing, (11th ed.). U.S.A.: Lippincott Company, 482609.

13. Kawar, M. (2013): Allergy \& Asthma Foundation of America, how to do just about everything?. Definition of asthma attack at: http://www.ehow.com/facts_5118258 definition-asthma-attack.htm, eHow, Inc. US. Accessed on 25-10-2013.

14. Ashery, R. (2011): Assessment nurses, performance in caring for 
Effect of Teaching Modules about Bronchial Asthma etc...

patients with bronchial asthma at Mansoura University and Emergency Hospital, unpublished Master Thesis, Faculty of Nursing, Zagazig University, pp.60-120.

15. Richard P. (2004): Impact of nurse practitioners on workload of general practitioners: randomised controlled trial, BMJ 2004; 328 doi: (Published 15 April 2004) Cite this as: BMJ 2004;328: 927 available at http://www.bmj.com

16. Daniels.E. Bacon J Denisio $\mathbf{S}$. (2005): Translation Squared: Improving Asthma Care for HighDisparity Populations Through a Safety Net Practice-Based Research Network, Vol. 42, No. 6 , P. 499-505.

17. John D., Ramona J., and b Jane M. (2004): Standardization as a Mechanism to Improve Safety in Health Care Joint Commission Journal on Quality and Patient Safety, Volume 30, Number 1, January 2004, pp. 5-14(10)

18. Salem, B. (2009): Care of patients with respiratory distress on mechanical ventilator, unpublished Master Thesis, Faculty of Nursing, Ain Shams University, 125-43.

19. Zytone, H. (2009): Effect of training program on nurses, knowledge and performance related to nursing care of post operative open heart patients in ICU at Zagazig University Hospital, unpublished Doctorate Dissertation, Faculty of Nursing, Zagazig University, 124-29.

20. Mohamed, S. (2009): Knowledge and practice of nurses dealing with pneumonia patients in Sharkia Governorate Hospitals, unpublished Master Thesis, Faculty of Nursing in Medical Surgical Nursing, Zagazig University, pp.70-77.

21. El-Ghadban, F. (2009): Assessment of nursing care given to patients with pneumonia, unpublished Master
Thesis, Faculty of Nursing, Ain Shams University, 123-49.

22. Powell, M. (2008): National asthma education and prevention program expert panel report 2: Guidelines for the diagnosis and management of asthma. Available at:http://www.nhlbi.nih.gov/guideline s/asthma/ asthgdln.htm Accessed on 22-2-2013.

23. Osborne, M., (2008): Assessing future need for acute care in adult asthmatics: The profile of asthma risk study: A prospective health maintenance organization-based study. Chest; 132:1151-61.

24. Sorrentino S. (2012): Mosby,s textbook for nursing assistants, (8th ed.). U.S., U.K.: Elsevier Inc. \& Mosby Inc., 582-663.

25. Hashem, S., (2000): Evaluation of nursing care provided for asthmatic patients during and after the attack, unpublished Master Thesis, Faculty of Nursing, Alexandria University, Egypt, 161-82.

26. Zytone, H. (2006): Assessment of nurses, knowledge and performance related to nursing care of post operative open heart patients in ICU at Zagazig University Hospital. Unpublished Master Thesis, Faculty of Nursing, Zagazig University, pp. 116-29.

27. Zatton, H. (2009): Assessment of knowledge and practice among nurses caring for patients with hepatitis, unpublished Master Thesis, Faculty of Nursing, Zagazig University, pp.120143.

28. Williams, E., and Bushong, E. (2009): Patient care, (3rd ed.). London: Mc Graw-Hill Co., 27-45.

29. Bowden, V., and Greenberg, C. (2009): Nursing procedures, (3rd ed.). Philadelphia: Lippincott Williams \& Wilkins Comp., 524. 
Reham El-Ashery Ashery Asker et. al.

30. Enarson, P., and Gie R. (2009): Management of pneumonia, International Journal of Tuberculosis and Lung Diseases, 9 (10):1083-87.

31. EImenem, H. (2008): Nursing care for patients undergoing non-invasive continuous positive airway pressure. Unpublished Master Thesis, Faculty of Nursing, Alexandria University, 30.

32. Mohamed, E. (2010): Assessment of nurses, performance related to nosocomial infection prevention in kidney dialysis units at Damietta City. Unpublished Master Thesis, Faculty of Nursing, Zagazig University, 11120.

33. Amin, F. (2005): Intervention nursing program for care of asthma at Mansoura University, unpublished doctorate dissertation, thesis in Medical Surgical Nursing, Faculty of Nursing, Ain Shams University, 92 94. 